\title{
ANALISIS AMPLIFIKASI DAN INDEKS KERENTANAN SEISMIK DI KAWASAN FMIPA UGM MENGGUNAKAN METODE HVSR
}

\author{
Nia Annisa Ferani Tanjung, Hakim Prima Yuniarto, Danang Widyawarman \\ Program Studi S1 Rekayasa Perangkat Lunak, Fakultas Teknologi Industri dan Informatika, Institut Teknologi Telkom \\ Purwokerto \\ e-mail : nia@ittelkom-pwt.ac.id
}

\begin{abstract}
Abstrak. Daerah Istimewa Yogyakarta merupakan kawasan cekungan yang tersusun atas endapan material vulkanik tebal dan merupakan kawasan aktif seismik. Gelombang seismik yang terjebak pada lapisan sedimen tebal dapat mengakibatkan kerusakan parah pada bangunan apabila terjadi gempa. Pemetaan mengenai kerentanan seismik di kawasan FMIPA UGM perlu dilakukan melihat bertambahnya gedung-gedung baru yang tinggi di area ini. Analisis amplifikasi dan frekuensi natural diolah menggunakan metode HVSR (Horizontal to Vertical Spectral Ratio), sehingga dihasilkan nilai indeks kerentanan seismik di daerah penelitian. Berdasarkan hasil penelitian, didapatkan bahwa nilai fekuensi natural (fo) di area penelitian berkisar antara $0.636-0.943 \mathrm{~Hz}$, Amplifikasi (Ao) berkisar antara 2.196 - 3.446 dan nilai kerentanan seismik $(K g)$ sebesar 5,291 - 18,677. Berdasarkan hasil pengolahan data yang didapat, dapat disimpulkan bahwa subsurface kawasan FMIPA UGM tersusun atas lapisan sedimen tebal dengan ketebalan antara 62.27-92.35 m. Hal ini berasosiasi terhadap area DIY yang tersusun di atas cekungan dengan material pengisi endapan vulkanik. Berdasarkan nilai $f o, A o$, dan $K g$, diketahui bahwa nilai kerentanan seismik yang paling tinggi terdapat di area gedung matematika FMIPA UGM.

Kata Kunci: Metode HVSR; fo; $\mathrm{Ao} ; \mathrm{Kg}$
\end{abstract}

Abstract. Yogyakarta Special Region is a basin area that is composed of thick material deposits and is an active seismic area. Seismic waves that is trapped in thick sedimentary layers can cause severe damage to buildings in the earthquake event. Mapping of seismic hazard in the FMIPA UGM area is important because in that area many new buildings are built. Analysis of amplification and natural frequency was processed using the HVSR (Horizontal to Vertical Spectra Ratio) method, so that the seismic hazard index was generated in the study area. Based on the resuts of the study, It was found that the natural frequency (fo) value in the study area ranged from $0.636-0.943 \mathrm{~Hz}$, amplification (Ao) ranged from $2.196-3.446$ and seismic hazard index $(\mathrm{Kg})$ ranged from 5,291 -18,677. Based on the results of data processing obtained, it can be concluded that the subsurface of the FMIPA UGM region is composed of thick sedimentary layers with a thickness of $\geq 30 \mathrm{~m}$. This is associated with the DIY area which is arranged on basin with volcanic deposits. Based on the fo, Ao, and $\mathrm{Kg}$ values, it is known that the highest seismic values are found in the mathematics building of FMIPA UGM area.

Keywords: HVSR method; fo; $\mathrm{Ao} ; \mathrm{Kg}$.

\section{PENDAHULUAN}

Daerah Istimewa Yogyakarta (DIY) secara geografis terbentang dari $7^{\circ} 33^{\prime}-8^{\circ} 15^{\prime}$ LS dan $110^{\circ} 5^{\prime}$ $110^{\circ} 50^{\prime}$ BT yang berbatasan dengan Gunungapi Vulkanik Merapi di sebelah utara dan zona aktif subduksi di sebelah selatan. Hal ini menyebabkan Yogyakarta dan sekitarnya banyak mengalami aktivitas seismik berupa gempabumi. Berdasarkan data historical gempa di Wilayah Yogyakarta, sedikitnya ada empat gempabumi dengan magnitudo besar dan sifatnya merusak, gempagempa tersebut disebabkan oleh ativitas tektonik zona aktif subduksi, yaitu pada tahun 1867, 1943, 1981, dan yang terakhir pada tahun 2006 (Setiyono, U, 2018). Gempa besar yang terjadi pada 27 Mei 2006 dengan skala magnitude 5,9 SR di wilayah Yogyakarta dan sekitarnya mengakibatkan banyaknya korban meninggal dan luka-luka serta kerusakan bangunan mulai dari rusak ringan hingga rata dengan tanah (Haifani, A. M., 2008). Berdasarkan penelitian (Sulaeman dkk., 2008), episentrum gempabumi diduga berlokasi lebih kurang $10 \mathrm{~km}$ sebelah timur Bantul yang berasosiasi dengan sesar Opak. 
Kerusakan gempabumi tidak hanya dipengaruhi oleh besarnya kekuatan gempa, akan tetapi juga dipengaruhi oleh kondisi geologi suatu wilayah (Daryono dkk., 2009). Daerah rawan kerusakan akibat gempabumi terjadi pada daerah sedimen lunak tebal yang berada di atas bedrock yang keras (Wulandari dkk., 2016). Semakin labil (lunak) batuan penyusun suatu wilayah, maka semakin besar pula efek gempabumi yang akan terjadi di kawasan tersebut. Hal ini dikarenakan wilayah yang labil mempunyai sifat batuan yang umumnya belum kompak, sehingga mudah terurai dan jika terjadi gempa, maka kerusakan akibat gempa akan semakin besar (Supartoyo, 2008).

Kawasan FMIPA UGM terletak di atas cekungan yang terdiri dari endapan material vulkanik merapi dengan komposisi tersusun atas aluvial, tuff, dan breksi agglomerate (Balai Statistik Daerah, B. D., 2017). Pada kawasan ini terdapat pembangunan gedung-gedung baru yang tinggi secara masif dalam kurun waktu 5 tahun terakhir. Oleh karena itu perlu dilakukan penelitian tentang indeks kerentanan seismik pada area FMIPA UGM untuk menentukan tingkat kerentanan area tersebut terhadap bencana gempabumi mengingat kawasan tersebut merupakan area publik yang sehari-harinya digunakan untuk aktivitas pendidikan.

Indeks kerentanan seismik dapat ditentukan dengan menggunakan metode HVSR yang disampaikan oleh Nakamura (1989) untuk memperkirakan nilai frekuensi natural dan faktor amplifikasi dari lapisan sedimen. Metode HVSR memanfaatkan getaran harmonik alami tanah yang disebabkan oleh kegiatan alam. Metode HVSR membandingkan antara rasio spektrum dari sinyal mikrotremor komponen horizontal terhadap komponen vertikalnya. Penelitian mikrozonasi gempa dengan menggunakan metode HVSR telah dilakukan telah dilakukan oleh beberapa peneliti di berbagai daerah di Indonesia (Arifin, 2014; R dkk., 2017; Sitorus dkk., 2017).

\section{TINJAUAN PUSTAKA}

\section{HVSR (Horizontal to Vertical Spectral Ratio)}

Metode HVSR pertama kali diperkenalkan oleh (Nogoshi dan Igarashi, 1971) yang menyatakan adanya hubungan antara perbandingan komponen horisontal dan vertikal terhadap kurva eliptisitas pada gelombang Rayleigh yang kemudian disempurnakan oleh (Nakamura, 1989; Nakamura, 2000) yang menyatakan bahwa perbandingan spektrum $H / V$ sebagai fungsi frekuensi berhubungan erat dengan fungsi site transfer untuk gelombang $\mathrm{S}$.

Prinsip dari metode HVSR yaitu menggunakan seismik pasif tiga komponen. Terdapat dua parameter penting yang didapatkan dari hasil pengolahan metode ini antara lain frekuensi natural (fo) dan amplifikasi (A). Kedua parameter ini pada dasarnya merupakan implementasi dari karakterisasi geologi suatu daerah. Langkah dari pengolahan metode HVSR adalah sebagai berikut:
a. Sensor mikroseismik merekam getaran.
b. Didapatkan time series data dari tiap-tiap komponen. Pada langkah ini dilakukan pemotongan sinyal ambient, agar dapat diolah pada langkah selanjutnya.
c. Spektrum fourier didapatkan dengan melakukan transformasi fourier pada tiap- tiap komponen (N-S, E-W dan vertikal).
d. Rata-rata dari 2 spektrum horizontal dihitung kemudian hasilnya dibagi oleh spektrum vertikalnya sehingga didapatkan kurva HVSR serta nilai dari (fo) dan (Ao).

\section{Transformasi Fourier}

Transformasi fourier di dalam mikroseismik adalah metode yang sering digunakan untuk mendekomposisi sebuah gelombang seismik menjadi beberapa gelombang harmonik sinusoidal dengan masing-masing frekuensi tertentu. Sedangkan kumpulan dari gelombang harmonik sinusoidal dikenal sebagai Deret Fourier. Transformasi Fourier digunakan untuk merubah data domain waktu ke dalam domain frekuensi. Hal ini dapat dilihat pada persamaan berikut : 


$$
F(w)=\int_{-\infty}^{\infty} f(t)^{-i w t} d t
$$

dengan $F(w)$ disebut sebagai transformasi fourier dari $f(t)$. Transformasi ini dapat dihitung lebih cepat menggunakan Fast Fourier Transform (FFT) pada komputasi digital.

\section{Frekuensi Natural (fo)}

Nilai frekuensi natural dari pengolahan HVSR menyatakan frekuensi alami yang terdapat di daerah tersebut. Hal ini menyatakan bahwa apabila terjadi gempa atau gangguan berupa getaran yang memiliki frekuensi yang sama dengan frekuensi natural, maka akan terjadi resonansi yang mengakibatkan amplifikasi gelombang seismik di area tersebut. Nilai frekuensi natural (fo) suatu wilayah menurut Mucciarelli dan Gallipoli (2001) didukung oleh beberapa faktor, yaitu ketebalan lapisan lapuk dan kecepatan rata-rata bawah permukaan $(V s)$, sehingga dapat ditulis dengan: $f o=V s / 4 H$

dengan fo adalah frekuensi natural, Vs adalah nilai rata-rata kecepatan gelombang geser pada kedalaman sampai dengan 30 meter dari permukaan, dan $H$ adalah ketebalan lapisan lapuk. . Berdasarkan persamaan (2), ketebalan lapisan lapuk adalah :

$H=\frac{V s}{4 f o}$

\section{Amplifikasi $(A o)$}

Amplifikasi pada gelombang seismik dapat disebabkan ketika suatu benda yang memiliki frekuensi diri, kemudian diusik oleh gelombang lain dengan frekuensi yang sama. Amplifikasi gelombang gempa bisa terjadi ketika gelombang merambat ke permukaan tanah dimana frekuensi natural (fo) tanah tersebut memiliki nilai frekuensi yang hampir sama atau sama dengan frekuensi gempa yang datang. Amplifikasi merupakan peristiwa penguatan suatu gelombang ketika melewati suatu medium tertentu. Perbandingan antara karakteristik sinyal horizontal terhadap sinyal vertikal berbanding lurus dengan penguatan gelombang pada saat melalui suatu medium.

\section{Nilai Kerentanan $(\boldsymbol{K g})$}

Salah satu parameter yang dinilai dalam pengukuran mikroseismik pada mikrozonasi gempa adalah adalah indeks kerentanan tanah $(K g)$. Nakamura (1989) menyatakan, Indeks Kerentanan $(K g)$ suatu wilayah mengindentifikasikan tingkat kerentanan suatu lapisan tanah yang mengalami deformasi akibat gempa bumi. Nilai kerentanan $(K g)$ dapat dicari dengan persamaan:

$$
K g=\frac{A o^{2}}{f_{o}}
$$

dengan Ao dan fo adalah amplitudo (faktor amplifikasi) dan frekuensi natural. Nilai $K g$ yang tinggi umumnya ditemukan pada tanah dengan litologi batuan sedimen yang lunak. Nilai yang tinggi tersebut mendeskripsikan bahwa daerah tersebut rentan terhadap gempa. Sebaliknya, nilai $K g$ yang kecil umumnya ditemukan pada tanah dengan batuan penyusun yang kuat dan stabil sehingga saat terjadi gempa, daerah tersebut hanya mengalami guncangan yang kecil.

\section{METODOLOGI}

Pengukuran mikrotremor dilakukan di Kawasan FMIPA UGM, Kecamatan Mlati, Kabupaten Sleman, Daerah Istimewa Yogyakarta. Data yang didapat berdasarkan hasil pengukuran di 19 titik dengan jarak antar titik 25-30 meter. Peta desain survey penelitian dapat dilihat pada Gambar 1.

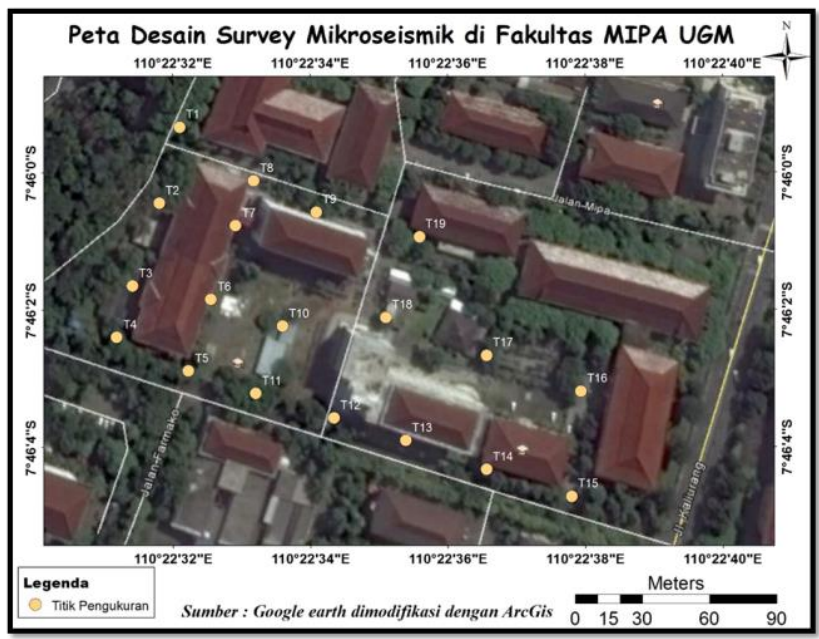

Gambar 1. Peta desain survey mikroseismik di kawasan Fakultas FMIPA UGM 
Penelitian dimulai dengan studi literatur, akuisisi data, pengolahan, hingga mengambil kesimpulan. Diagram alir penelitian dapat dilihat pada Gambar 2.

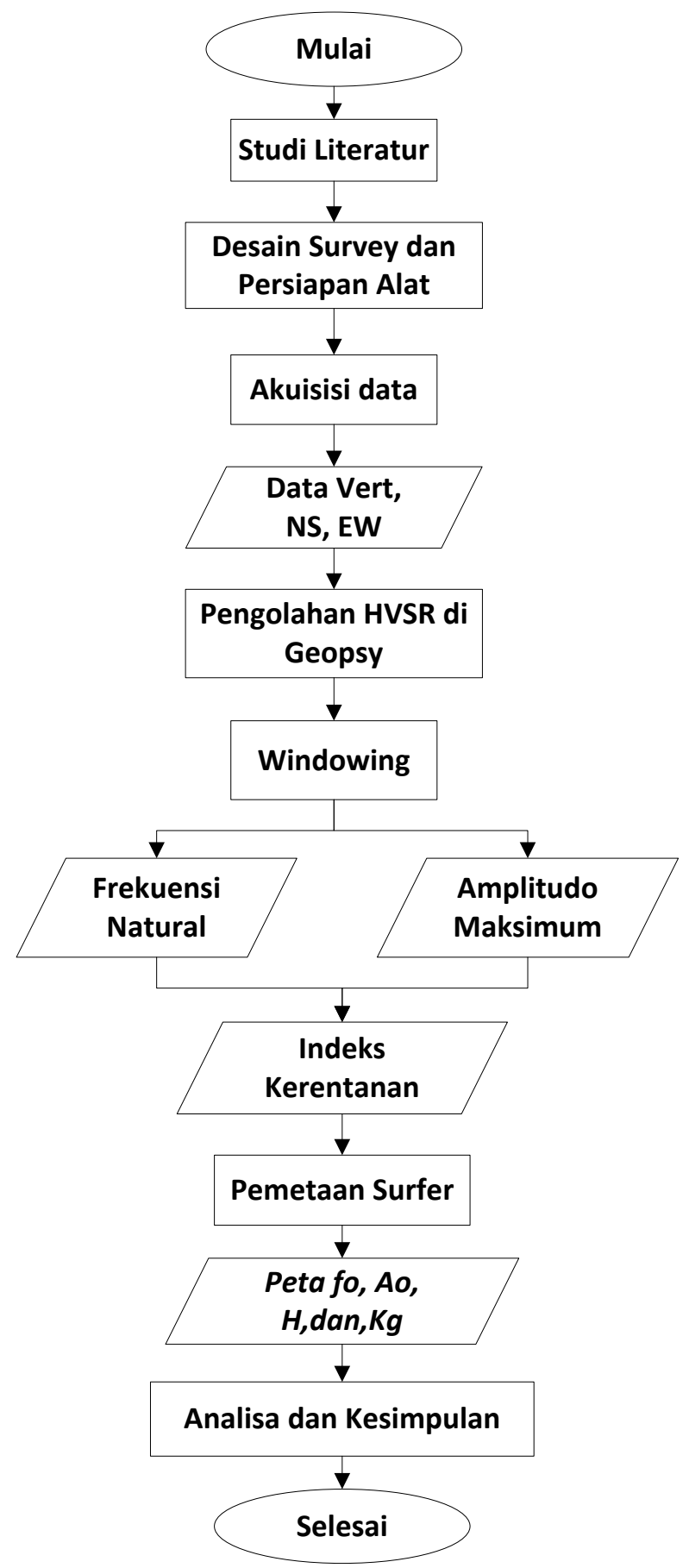

Gambar 2. Diagram alir penelitian

Alat yang digunakan dalam penelitian ini adalah seismometer Lennartz Electronic tipe LE$3 D / 20$ s dengan 3 komponen (Vertikal, Utara-
Selatan, Barat-Timur). Frekuensi natural yang dimiliki oleh sensor ini adalah $0,05 \mathrm{~Hz}$ dengan upper frequency-nya $50 \mathrm{~Hz}$. Waktu yang digunakan untuk melakukan perekaman pada penelitian ini adalah 40-50 menit di setiap titik.

Data yang diperoleh diolah menggunakan software (perangkat lunak) Geopsy guna mendapatkan nilai frekuensi natural dan Amplitudo maksimumnya melalui proses analisa HVSR. Untuk menghilangkan atau mengurangi gangguan (noise) pada sinyal yang diperoleh maka dalam proses pengolahan data dilakukan filtering, untuk mendapatkan sinyal utama yang diharapkan. Tahap berikutnya adalah melakukan penjendelaan waktu (windowing) secara manual. Pemilihan secara manual dilakukan untuk dapat memilih sinyal dalam window waktu tertentu yang kurang memiliki gangguan (noise), serta dipilih sinyal yang paling stasioner. Setelah proses penjendelaan waktu (windowing) selesai maka ketiga komponen sinyal yang terdiri atas komponen Utara-Selatan, TimurBarat, dan Atas-Bawah akan di analisis menggunakan HVSR, dimana setelah analisa HVSR ini akan diperoleh nilai frekuensi natural $(f o)$ dan amplifikasinya $(A o)$. Nilai kerentanan seismik $(K g)$ dapat dicari dengan menggunakan persamaan (4) yaitu dengan membagikan nilai Amplitudo maksimum kuadrat terhadap nilai frekuensi naturalnya.

\section{HASIL DAN PEMBAHASAN}

\section{Frekuensi Natural (fo)}

Nilai frekuensi natural menggambarkan ketebalan lapisan lapuk di bawah permukaan dan kecepatan gelombang yang melalui medium tersebut (Mucciarelli dan Gallipoli, 2001). Semakin besar nilai suatu frekuensi natural, maka semakin kecil ketebalan lapisan lapuknya, begitu juga sebaliknya. Apabila nilai frekuensi natural tinggi, maka suatu daerah cenderung tingkat kerawanannya rendah.

Karakteristik batuan bawah permukaan dapat diketahui dari nilai frekuensi naturalnya. Pada tahun 1981, Kanai melakukan penelitian mengenai pegklasifikasian tanah berdasarkan nilai frekuensi natural. Hal ini dapat dilihat pada Tabel 1. 
Berdasarkan hasil penelitian, nilai persebaran frekuensi natural di kawasan FMIPA UGM dapat dilihat pada Gambar 3 dan ketebalan lapisan sedimen pada Gambar 4.

Tabel 1. Klasifikasi tanah berdasarkan nilai frekuensi natural mikroseismik oleh Kanai (BMKG, 1998)

\begin{tabular}{|c|c|c|c|c|}
\hline \multicolumn{2}{|c|}{$\begin{array}{c}\text { Klasifikasi } \\
\text { tanah }\end{array}$} & \multirow{2}{*}{$\begin{array}{c}\text { Frekuensi } \\
\text { Natural } \\
(\mathrm{Hz})\end{array}$} & \multirow[t]{2}{*}{ Klasifikasi Kanai } & \multirow[t]{2}{*}{ Deskripsi } \\
\hline Tipe & Jenis & & & \\
\hline $\begin{array}{l}\text { Tipe } \\
\text { IV }\end{array}$ & $\begin{array}{c}\text { Jenis } \\
\text { I }\end{array}$ & $6,667-20$ & $\begin{array}{l}\text { Batuan tersier } \\
\text { atau lebih tua. } \\
\text { Terdiri dari } \\
\text { batuan Hard } \\
\text { sandy, gravel, } \\
\text { dan lainnya. }\end{array}$ & $\begin{array}{l}\text { Ketebalan } \\
\text { sedimen } \\
\text { permukaan } \\
\text { sangat tipis, } \\
\text { didominasi } \\
\text { oleh batuan } \\
\text { keras. }\end{array}$ \\
\hline $\begin{array}{l}\text { Tipe } \\
\text { III }\end{array}$ & $\begin{array}{c}\text { Jenis } \\
\text { II }\end{array}$ & $4,0-10$ & $\begin{array}{c}\text { Batuan tersier } \\
\text { atau lebih tua. } \\
\text { Terdiri dari } \\
\text { batuan Hard } \\
\text { sandy, gravel, } \\
\text { dan lainnya. }\end{array}$ & $\begin{array}{l}\text { Ketebalan } \\
\text { sedimen } \\
\text { permukaan } \\
\text { masuk } \\
\text { dalam } \\
\text { kategori } \\
\text { menengah } \\
\text { 5-10m. }\end{array}$ \\
\hline $\begin{array}{c}\text { Tipe } \\
\text { II }\end{array}$ & $\begin{array}{c}\text { Jenis } \\
\text { III }\end{array}$ & $2,5-4$ & $\begin{array}{l}\text { Batuan alluvial, } \\
\text { dengan } \\
\text { ketebalan lebih } \\
\text { dari } 5 \mathrm{~m} \text {. Terdiri } \\
\text { dari sandy } \\
\text { gravel, sandy } \\
\text { hard clay, loam, } \\
\text { dan lainnya. }\end{array}$ & $\begin{array}{l}\text { Ketebalan } \\
\text { sedimen } \\
\text { permukaan } \\
\text { masuk } \\
\text { dalam } \\
\text { kategori } \\
\text { tebal, sekitar } \\
\text { 10-30m. }\end{array}$ \\
\hline $\begin{array}{l}\text { Tipe } \\
\text { I }\end{array}$ & $\begin{array}{l}\text { Jenis } \\
\text { IV }\end{array}$ & $\begin{array}{l}\text { Kurang dari } \\
\quad 2,5\end{array}$ & $\begin{array}{l}\text { Batuan alluvial, } \\
\text { yang terbentuk } \\
\text { dari sedimentasi } \\
\text { deta, top soil, } \\
\text { lumpur, dan } \\
\text { lainnya. } \\
\text { Kedalaman } \\
\geq 30 \mathrm{~m} .\end{array}$ & $\begin{array}{l}\text { Ketebalan } \\
\text { sedimen } \\
\text { permukaan } \\
\text { sangatlah } \\
\text { tebal. }\end{array}$ \\
\hline
\end{tabular}

Berdasarkan hasil pengolahan nilai frekuensi natural di daerah penelitian, diperoleh range nilai frekuensi natural (fo) sebesar 0,636 - 0,943 Hz. Jika ditinjau dari Tabel 1, maka nilai frekuensi natural di kawasan FMIPA UGM berada pada klasifikasi tanah tipe 1 jenis IV, dimana tersusun atas batuan alluvial yang terbentuk dari sedimentasi dengan kedalaman $\geq 30 \mathrm{~m}$. Ketebalan lapisan sedimen dihitung dengan menggunakan persamaan 3. Hal ini berasosiasi terhadap penelitian (Haifani, A. M., 2008) yang mengatakan bahwa area penelitian terletak di atas cekungan yang terdiri dari endapan material vulkanik merapi dengan komposisi tersusun atas aluvial, tuff, dan breksi agglomerate (Balai Statistik Daerah, B. D., 2017).

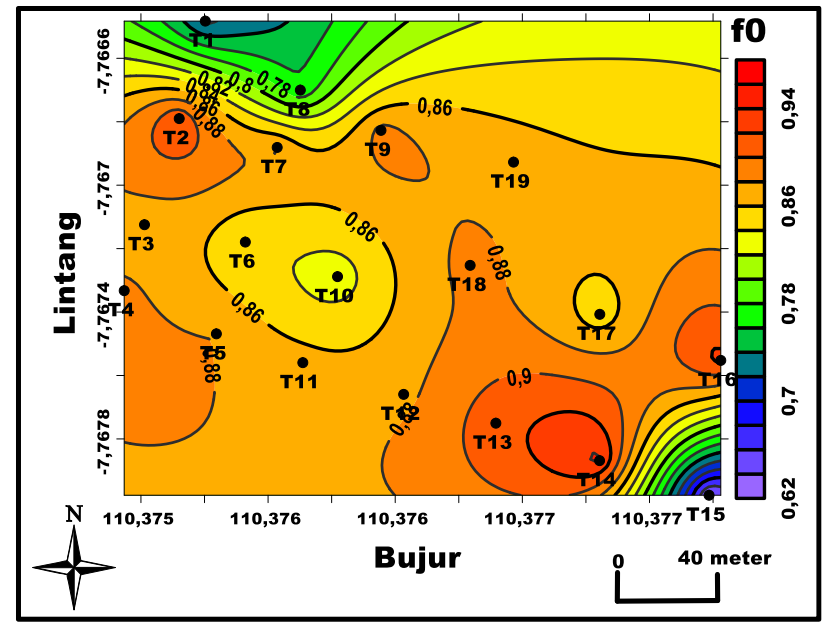

Gambar 3. Peta persebaran nilai frekuensi natural di sekitar kawasan FMIPA UGM

Nilai frekuensi natural tertinggi terlihat di sekitar titik T14 yaitu 0,943 Hz. Area ini merupakan kawasan gedung SIC berlantai tiga dan gedung perkuliahan S1 berlantai lima yang baru saja selesai dibangun pada tahun 2015. Nilai frekuensi natural yang tinggi terlihat juga di area titik T2 sekitar 0,918 $\mathrm{Hz}$ dan T9 sekitar 0,886 Hz. Hal ini berasosiasi terhadap gedung Prodi Fisika berlantai tiga dan gedung S2/S3 berlantai 5 .

Nilai frekuensi natural yang rendah terlihat di sekitar titik T15 sekitar 0,636 Hz. Area ini merupakan kawasan gedung matematika berlantai tiga. Hal ini menandakan bahwa lapisan sedimen di sekitar area gedung matematika lebih tebal dibandingkan area lain di kawasan FMIPA UGM. Nilai frekuensi natural yang rendah juga terlihat di area titik T1 sekitar $0,714 \mathrm{~Hz}$. Hal ini berasosiasi dengan hutan biologi yang terdapat di sebelah barat kawasan FMIPA UGM.

Ketebalan lapisan sedimen bawah permukaan area FMIPA UGM, dihitung dengan menggunakan persamaan 3. Nilai Vs yang digunakan dalam penelitian ini mengacu pada hasil penelitian Muzli, dkk. (2016) mengenai pengukuran nilai Vs30 di wilayah Yogyakarta dengan menggunakan metode MASW. Peta persebaran lapisan sedimen di area FMIPA UGM dapat dilihat pada Gambar 4. 


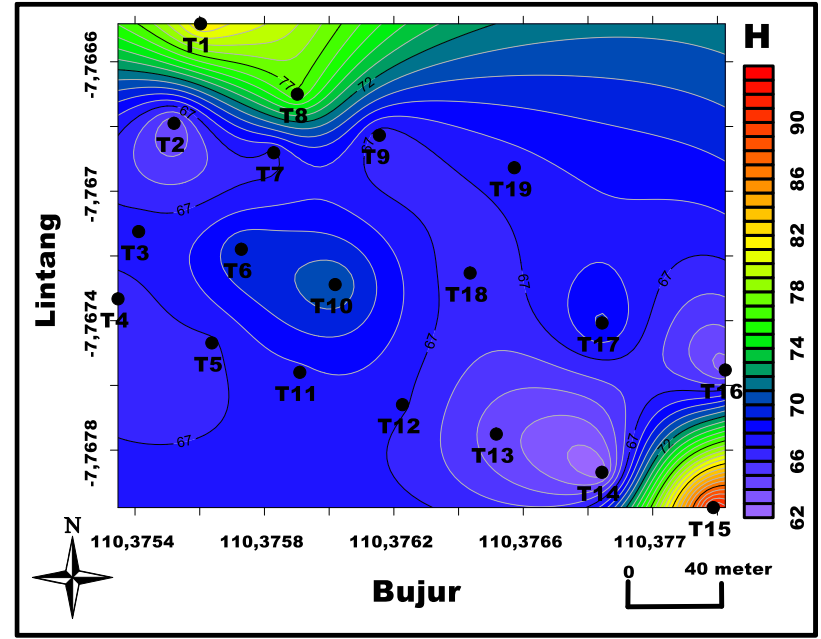

Gambar 4. Peta persebaran nilai ketebalan lapisan sedimen di sekitar kawasan FMIPA UGM

Ketebalan lapisan sedimen di kawasan FMIPA UGM berkisar antara 62,27m-92,53m. Berdasarkan peta persebarannya, area yang memiliki ketebalan lapisan sedimen paling tinggi di sekitar titik T15. Hal ini berasosiasi terhadap gedung matematikan FMIPA UGM berlantai 3.

\section{Amplifikasi (Ao)}

Amplifikasi merupakan nilai amplitudo maksimum yang didapatkan dari pengolahan data mikroseismik. Tabel 2 menunjukkan klasifikasi amplifikasi berdasarkan besarnya nilai amplifikasi suatu daerah (Setiawan, J.R., 2009).

Tabel 2. Klasifikasi nilai amplifikasi

\begin{tabular}{ccc}
\hline Zona & Klasifikasi & Nilai Faktor Amplifikasi \\
\hline 1 & Rendah & Ao $<3$ \\
\hline 2 & Sedang & $3 \leq$ A $0<6$ \\
\hline 3 & Tinggi & $6 \leq$ Ao $<9$ \\
\hline 4 & Sangat Tinggi & Ao $\geq 9$ \\
\hline
\end{tabular}

Berdasarkan data hasil pengukuran yang diambil pada 19 titik pengukuran, nilai amplifikasi di kawasan FMIPA UGM berkisar 2,196 - 3,446. Jika ditinjau dari Tabel 2, maka wilayah kawasan UGM masuk ke dalam kategori amplifikasi rendah hingga sedang. Nilai persebaran amplifikasi di kawasan FMIPA UGM dapat dilihat pada Gambar 5.

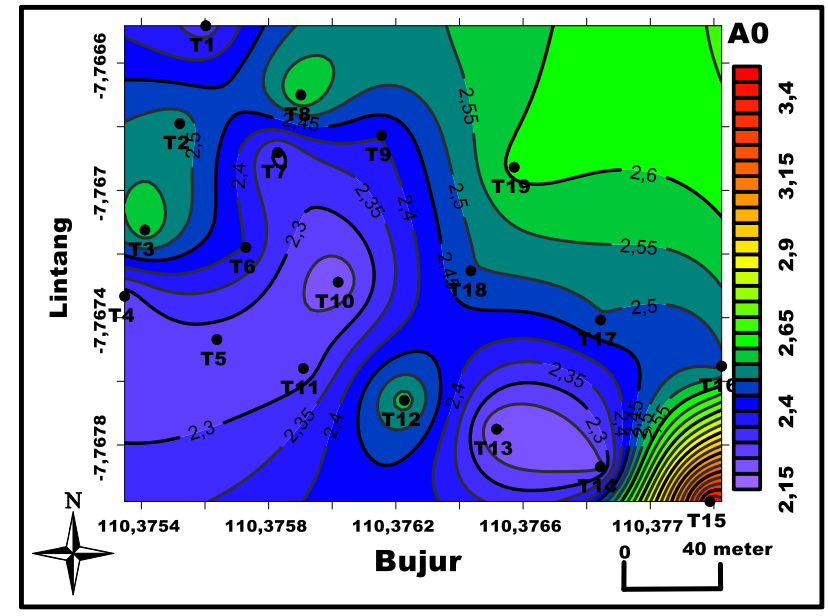

Gambar 5. Peta persebaran nilai Amplitudo maksimum di sekitar kawasan FMIPA UGM

Nilai amplifikasi tertinggi terlihat di sekitar titik T15 yaitu sebesar 3,446. Hal ini menandakan bahwa di sekitar area T15 memiliki kecenderungan kerusakan yang lebih tinggi daripada area yang lain jika terjadi gempa. Nilai amplifikasi menengah terlihat di sekitar titik T3 dan T8 yang berasosiasi dengan gedung prodi Fisika berlantai 3.

\section{Indeks Kerentanan Seismik (Kg)}

Indeks kerentanan seismik $(\mathrm{Kg})$ atau sering disebut sebagai indeks kerentanan gempa menggambarkan tingkat kerentanan lapisan tanah permukaan terhadap deformasi saat terjadi gempabumi. Berdasarkan rumus dan perhitungan yang telah dilakukan, maka nilai dari indeks kerentanan gempa sangat dipengaruhi oleh amplitudo maksimum dan frekuensi natural. Ketika nilai amplitudo besar dan nilai frekuensi natural kecil, maka nilai dari indeks kerentanan gempa akan semakin besar. sebaliknya, jika nilai amplitudo kecil dan nilai frekuensi natural besar, maka nilai dari indeks kerentanan gempa akan semakin kecil.

Berdasarkan data hasil pengukuran yang diambil pada 19 titik pengukuran, nilai indeks kerentanan seismik di kawasan FMIPA UGM berkisar antara 5,291-18,677. Hal ini dapat dilihat pada Gambar 6. 


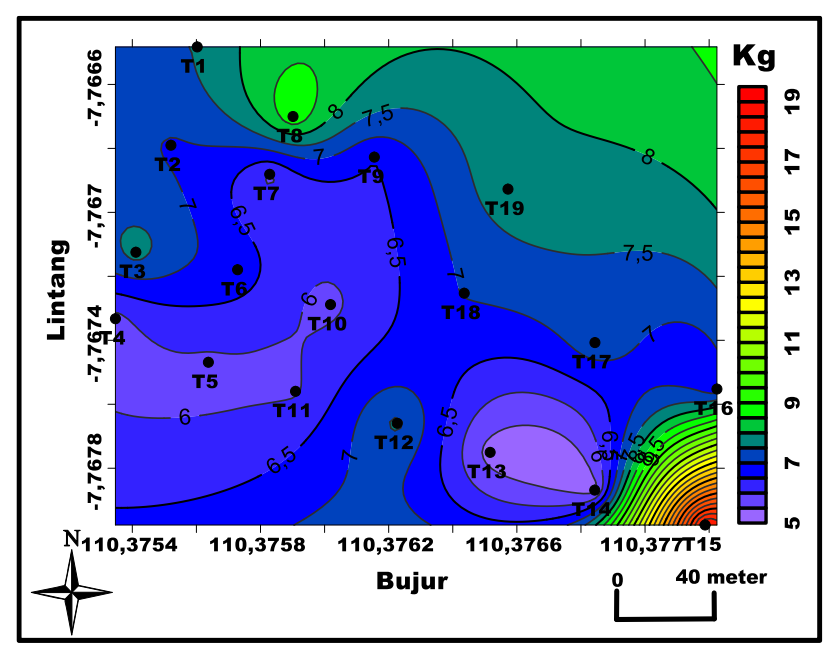

Gambar 6. Peta persebaran kerentanan seismik di kawasan FMPA UGM

Kerentanan seismik yang tertinggi terlihat berada di sekitar titik T15 yaitu sebesar 18,677. Area ini berasosiasi dengan gedung matematika Fakultas FMIPA UGM. Jika terjadi suatu guncangan di area yogyakarta dan sekitarnya, area T15 merupakan area yang paling rawan dibandingkan area yang lain di kawasan FMIPA UGM.

\section{PENUTUP}

\section{Simpulan}

Berdasarkan hasil dan pembahasan dari penelitian, dapat disimpulkan bahwa :

1. Nilai frekuensi natural di kawasan FMIPA UGM berkisar antara 0,636-0,943 Hz. Hal ini menunjukkan bahwa kawasan FMIPA UGM berada pada klasifikasi tanah tipe 1 jenis IV, dimana tersusun atas batuan alluvial yang terbentuk dari sedimentasi dengan ketebalan sekitar 62,27m-92,53m.

2. Apabila terjadi gempabumi, amplifikasi dan indeks kerentanan seismik tertinggi terjadi di sekitar titik T15 yang berasosiasi dengan gedung matematika FMIPA UGM.

\section{Saran}

Saran yang dapat diberikan berdasarkan hasil penelitian untuk membangun hipotesa-hipotesa selajutnya adalah :

1. Perlu ditambahkan titik-titik pengukuran mikroseismik di kawasan UGM, menilik masifnya pembangunan gedung-gedung tinggi di kawasan UGM.

2. Perlu dilakukan penelitian lebih lanjut mengenai pemodelan likuifaksi di area penelitian, dikarenakan area penelitian berada di kawasan aktif seismik dan tersusun atas lapisan sedimen tebal material endapan vulkanik.

\section{Ucapan Terima Kasih}

Penulis mengucapkan terimakasih kepada semua rekan yang telah membantu dalam proses akuisisi data dan keluarga besar S2 IImu Fisika/Geofisika UGM yang telah memberikan arahan dan masukan selama mengerjakan penelitian ini.

\section{DAFTAR PUSTAKA}

Arifin, S.S. (2014), "PENENTUAN ZONA RAWAN GUNCANGAN BENCANA GEMPA BUMI BERDASARKAN ANALISIS NILAI AMPLIFIKASI HVSR MIKROTREMOR DAN ANALISIS PERIODE DOMINAN DAERAH LIWA DAN SEKITARNYA", JGE (Jurnal Geofisika Eksplorasi), Vol.2, No.01, hal. 30-40.

http://doi.org/10.23960/jge.v2i01.217.

Balai Statistik Daerah, B. D. (2017), Geoportal Daerah Istimewa Yogyakarta Diambil dari http://gis.jogjaprov.go.id/documents/31.

BMKG (1998), "Sumber Daya Geologi", Buletin Meteorologi dan Geofisika No.4,

Daryono, Sutikno, J. Sartohadi dan K.S Brotopuspito (2009), "Pengkajian Local Site Effect di Graben Bantul Menggunakan Indeks Kerentanan Seismik Berdasarkan Pengukuran Mikrotremor", Jurnal Kebencanaan Indonesia, Vol.2, No.2, hal. 456-467.

Haifani, A. M. (2008), "Manajemen Resiko Bencana Gempa Bumi (Studi Kasus Gepabumi Yogyakarta 27 Mei 2006)", Seminar Nasional IV,.

Mucciarelli, M. dan Gallipoli, M. (2001), "A critical review of 10 years of microtremor HVSR technique", 
Bollettino di Geofisica Teorica ed Applicata, Vol.42, hal. 255-266.

Muzli, M., Mahesworo, R.P., Madijono, R., Siswoyo, S., Pramono, S., Dewi, K.R., Budiarta, B., Sativa, O., Sulistyo, B., Swastikarani, R., Oktavia, N., Moehajirin, M., Efendi, N., Wijaya, T.A., Subadyo, B., Mujianto, M., Suwarto, S. dan Pramono, S. (2016), "PENGUKURAN VS30 MENGGUNAKAN METODE MASW UNTUK WILAYAH YOGYAKARTA", Jurnal Meteorologi dan Geofisika, Vol.17, No.1. http://doi.org/10.31172/jmg.v17i1.374.

Nakamura, Y. (1989), "A METHOD FOR DYNAMIC CHARACTERISTICS ESTIMATION OF SUBSURFACE USING MICROTREMOR ON THE GROUND SURFACE", Railway Technical Research Institute, Quarterly Reports, Vol.30, No.1. Diambil dari https://trid.trb.org/view/294184.

Nakamura, Yutaka (2000), "Clear identification of fundamental idea of Nakamura's technique and its applications", Proceedings of the XII World Conference Earthquake Engineering, Vol.Paper no 2656.

Nogoshi, M. dan Igarashi, T. (1971), "On the Amplitude Characteristics of Microtremor (Part 2)", Zisin (Journal of the Seismological Society of Japan. 2nd ser.), Vol.24, No.1, hal. 26-40. http://doi.org/10.4294/zisin1948.24.1_26.

R, A.P., Purwanto, M.S. dan Widodo, A. (2017), "Identifikasi Percepatan Tanah Maksimum (PGA) Dan Kerentanan Tanah Menggunakan Metode Mikrotremor Jalur Sesar Kendeng", Jurnal Geosaintek, Vol.3, No.2, hal. 107-114114.

http://doi.org/10.12962/j25023659.v3i2.2966.

Setiawan, J.R. (2009), Mikrozonasi Seismisitas Daerah Yogyakarta dan Sekitarnya, Institut Teknologi Bandung, Bandung.

Setiyono, U (2018), Katalog Gempabumi Signifikan dan merusak 1821-2017, BMKG, Jakarta.

Sitorus, N., Purwanto, S. dan Utama, W. (2017), "Analisis Nilai Frekuensi Natural Dan Amplifikasi Desa Olak Alen Blitar Menggunakan Metode Mikrotremor HVSR", Jurnal Geosaintek, Vol.3,
No.2, hal. 89-92-92. http://doi.org/10.12962/j25023659.v3i2.2962.

Sulaeman, C., Cendekia Dewi, L. dan Triyoso, W. (2008), "Karakterisasi sumber gempa Yogyakarta 2006 berdasarkan data GPS", Indonesian Journal on Geoscience, Vol.3. http://doi.org/10.17014/ijog.3.1.49-56.

Supartoyo (2008), Open Library ID: OL24027099M, Katalog gempabumi merusak di Indonesia tahun 1629-2007, Departemen Energi dan Sumber Daya Mineral, Badan Geologi, Pusat Vulkanologi dan Mitigasi Bencana Geologi, Bandung.

Wulandari, A., Suharno, S., Rustadi, R. dan Robiana, R. (2016), "PEMETAAN MIKROZONASI DAERAH RAWAN GEMPABUMI MENGGUNAKAN METODE HVSR DAERAH PAINAN SUMATERA BARAT", JGE (Jurnal Geofisika Eksplorasi), Vol.4, No.1, hal. 33-48. http://doi.org/10.23960/jge.v4i1.1054. 